\title{
GAMBARAN PENGETAHUAN IBU PRIMIGRAVIDA TENTANG POSISI DALAM MELAHIRKAN DI KLINIK BIDAN KRISTIN TITI PAPAN KOTA MEDAN TAHUN 2018
}

\author{
Netty Herawaty Purba ${ }^{1}$, Elviana Silaen ${ }^{2}$, Riska Mulyani $^{3}$ \\ ${ }^{1}$ Dosen Prodi D III Kebidanan STIKes Imelda Medan \\ ${ }^{2}$ Mahasiswa Prodi D III Kebidanan STIKes Imelda Medan \\ ${ }^{3}$ Mahasiswa Prodi D III Kebidanan STIKes Imelda Medan
}

\begin{abstract}
ABSTRAK
Persalinan mengenal empat teknik bersalin, selama teknik itu tidak ada yang sulit, justru dengan teknik-teknik tersebut ibu akan semakin mudah dan nyaman menjalani proses bersalin karena itu bisa menentukan sendiri yang mana teknik bersalin yang paling baik buat dirinya. Penelitian ini bertujuan untuk mengetahui bagaimana pengetahuan ibu primigravida tentang posisi dalam melahirkan di Klinik Bidan Kristin Titi Papan Kota Medan Tahun 2018. Penelitian ini bersifat deskriftif dengan menggunakan data primer, dengan populasi 30 Responden dengan sampel 30 Responden dengan menggunakan total sampling, teknik pengumpulan data telah dilakukan dengan cara mambagikan kuesioner. Dari hasil penelitian diketahui bahwa berdasarkan pengetahuan ibu dikategorikan mayoritas berpendidikan SMP sebanyak 14 orang $(46,7 \%)$ dan minoritas berpendidikan SD sebanyak 3 orang $(10 \%)$. Berdasarkan sumber informasi mayoritas ibu mendapatkan informasi dari tenaga kesehatan sebanyak 22 orang $(73,3$ $\%)$ dan minoritas ibu mendapatkan informasi dari masyarakat sebanyak 3 orang (10 \%). Dan berdasarkan paritas mayoritas ibu berparitas 3 kali sebanyak 12 orang (40\%) dan minoritas ibu berparitas 1 orang sebanyak 1 orang $(3,3 \%)$. Dari hasil penelitian tersebut dapat disimpulkan bahwa pengetahuan ibu hamil tentang posisi dalam melahirkan cukup baik, maka diharapkan kepada masyarakat untuk lebih aktif dan meningkatkan derajat kesehatan masyarakat itu sendiri, dan diharapkan kepada tenaga kesehatan agar tidak bosan-bosan memberikan pengarahan dan penyuluhan kepada masyarakat agar terciptanya Indonesia sehat 2011.
\end{abstract}

Kata kunci : Pengetahuan, Primigravida, Posisi Melahirkan.

\section{PENDAHULUAN}

AngkaKematian Ibu (AKI) merupakan masalah yang sedang dihadapi bangsa kita, salah satu penyumbang AKI adalah tentang persalinan. Persalinan adalah proses pengeluaran hasil konsepsi (janin dan plasenta) yang telah telah cukup bulan atau dapat hidup di luar kandungan melalui jalan lahir atau melalui jalan lain dengan bantuan atau tanpa bantuan (kekuatan sendiri). ${ }^{1}$

Dalam abad ke XVIII Ahli Obstetri dari Prancis pada The Queen of France, memperkenalkan posisi horizontal tersebut untuk persalinan, posisi horizontal ini membantu karena memudahkan penatalaksanaan oleh penolong, bukan memberi keuntungan untuk ibu dan janin. Selama akhir 1900-an posisi dorsal rekumben untuk persalinan telah menghilangkan penggunaan posisi ini, untuk ibu bersalin di Amerika Serikat. ${ }^{2}$

Tidak ada posisi yang paling baik namun posisi yang dirasakan paling nyaman oleh ibu, maka itu adalah posisi yang terbaik. Pada umumnya ketika melahirkan Dokter akan meminta ibu untuk berbaring atau setengah duduk. Tetapi pada saat proses persalinan berlangsung tidak menutup kemungkinan Dokter akan meminta untuk mengubah posisi agar persalinan berjalan lancar, seperti mengubah posisi menjadi miring karena proses persalinan berjalan lamban atau sulit. $^{3}$ 
Posisi-posisi dalam tiap kategori menyebabkan perubahan fisik yang serupa ada tujuh, yaitu: Pertama: Posisi setengah duduk atau miring adalah posisi istirahat dan netral terhadap gaya gravitasi, poisisi itu akan membantu seorang wanita yang kelelahan untuk menghemat energinya, terutama jika ia lelah berdiri dan berjalan untuk jangka waktu yang lama, jika kemajuan terjadi cepat, netralisasi gravitasi dapat memperlambat persalinan sampai pada kecepatan yang dapat dikendalikan. Kedua: Posisi tegak memanfaatkan gaya gravitasi untuk menempatkan presentasi (bagian terbawah) diserviks, meningkatkan kualitas kontraksi dan menambah penurunan janin. Ketiga: Posisi dengan wanita bersandar kedepan cenderung untuk meningkatkan rotasi janin dan mengurangi nyeri punggung. Keempat: Posisi Asimetris dengan wanita meninggikan salah satu kaki. Kelima: Cenderung meningkatkan rotasi dan mengurangi nyeri punggung. Keenam: Posisi litotomi berlebih, yang digunakan ketika beberapa kontraksi terjadi pada kala II, dapat memfasilitasi jalan lahir, janin yang terperangkap dibawah simpisis pubis. Ketujuh: Posisi dorsal cenderung menyebabkan hipotensi supine dan meningkatkan nyeri punggung, kontraksi akan semakin sering dan nyeri, tetapi tidak mempercepat kemajuan persalinan. ${ }^{4}$

Ternyata teknik bersalin pervaginam yang berkonvensial tidak melalui dengan dengan cara setengah berbaring seperti yang kita kenal selama ini, menurut dr. Alfiber, Sp. OG dari Rumah Sakit Hospital Cinere, persalinan mengenal empat teknik bersalin, selama teknik ini tidak ada yang sulit justru dengan teknik-teknik itu ibu akan semakin mudah dan nyaman menjalani proses bersalin karena itu bisa menentukan sendiri yang mana teknik bersalin yang paling baik buat dirinya. ${ }^{5}$

\section{TINJAUAN PUSTAKA}

Pengetahuan adalah merupakan pengetahuan tersusun secara sistematis dengan menggunakan kekuatan pikiran, Pengetahuan yang mana selalu dapat diperiksa atau ditelaah.

Masa kehamilan dimulai dari konsepsi sampai lahirnya janin, lamanya hamil normal adalah 280 hari (40 minggu atau 9 bulan 7 hari) dihitung dari pertama haid terakhir, kehamilan dibagi dalam 3 triwulan yaitu: triwulan pertama dimulai dari konsepsi sampai 3 bulan, triwulan kedua dari bulan keempat sampai 6 bulan, triwulan ketiga dari bulan ketujuh sampai 9 bulan. (Saifuddin AB, 2006)

Posisi yang paling baik pada saat persalinan adalah posisi yang dirasakan paling nyaman oleh ibu maka itu adalah posisi yang terbaik. Pada umumnya ketika melahirkan dokter akan meminta ibu untuk berbaring atau setengah duduk, tapi pada saat proses persalinan berlangsung, tidak menutup kemungkinan dokter akan meminta ibu mengubah posisi menjadi miring karena proses persalinan berjalan lamban dan sulit.

Empat posisi bersalin dengan kelebihan dan kekurangannya: a. Posisi berbaring atau litotomi. Dimana siibu telentang didapat tidur bersalin dengan menggantung kedua pahanya pada penopang kursi khusus untuk bersalin. Kelebihan: Dokter lebih leluasa membantu proses persalinan. Jalan lahir pun menghadap kedepan, sehingga dokter dapat lebih mudah mengukur perkembangan pembukaan dan waktu persalinan bisa diprediksi secara lebih akurat, kepala bayi mudah dipegang dan diarahkan, sehingga apabila terjadi perubahan posisi kepala bayi, dokter langsung bisa mengarahkan pada posisi yang seharusnya. Kelemahan: Posisi berbaring membuat ibu sulit untuk mengedan, karena gaya berat tubuh ibu yang berada dibawah sejajar dengan posisi bayi. Posisi ini pun diduga bisa mengakibatkan perineum (daerah diantara anus dan vagina) maregang sedemikian rupa sehingga menyulitkan persalinan. Pengiriman oksigen melalui darah yang mengalir dari ibu ke janin melalui plasenta relatif berkurang, karena letak pembuluh 
besar berada dibawah posisi bayi dan tekanan oleh masa/berat badan bayi. Apalagi jika letak plasenta juga berada dibawah bayi.Akibatnya tekanan pada pembuluh darah bisa meninggi dan menimbulkan perlambatan peredaran darah balik ibu. b. Posisi miring atau lateral. Ibu berbaring miring kekiri atau kekanan dengan salah satu kaki diangkat sedangkan kaki lainnya dalam keadaan lurus, posisi ini umumnya dilakukan bila posisi kepala bayi belum tepat. Kelebihan : Selain peredaran darah balik dari ibu bisa mengalir lancar, pengiriman oksigen dalam darah dari ibu kejanin melalui plasenta juga tidak terganggu, sehingga proses pembekuan akan berlangsung secara perlahan - lahan sehingga persalinan berlangsung lebih nyaman. Kelemahan: Posisi miring ini menyulitkan dokter untuk membantu proses persalinan karena latel kepala bayi susah di monitor, dipegang, maupun diarahkan. Dokterpun akan mengalami kesulitan saat melakukan tindakan episiotomi. c. Posisi jongkok. Dimana biasanya ibu berjongkok diatas bantalan empuk yang berguna manahan kepala dan tubuh bayi. Kelebihan : Merupakan posisi bersalin alami, karena memanfaatkan gaya gravitasi bumi, sehingga ibu tidak susah, terlalu kuat mengedan. Kekurangan. Selain berpeluang membuat cedera kepala bayi, posisi ini dinilai kurang menguntungkan karena penyulit memantau perkembangan pembukaan dan tindakan-tindakan penilaian lainnya, misalnya episiotomi. d. Posisi setengah duduk. Pada posisi ini, ibu duduk dengan punggung bersandar bantal, kaki di tekuk dan paha dibuka kearah samping.Posisi ini cukup membuat ibu nyaman. Kelemahan: Sumbu jalan lahir yang perlu ditempuh janin untuk bisa keluar jadi lebih pendek. Suplai oksigen dari ibu kejanin pun juga dapat berlangsung secara maksimal. Kelemahan: Posisi dapat menimbulkan rasa lelah dan keluhan punggung pegal, Apalagi jika proses persalinan tersebut berlangsung lama.

\section{METODE PENELITIAN}

Rancangan penelitian penelitian bersifat deskriftif dengan metode survey yang digunakan untuk mengetahui Gambaran pengetahuan ibu primigravida tentang posisi dalam melahirkan di Klinik Bidan Kristin Titi Papan Kota Medan Tahun 2018. Penelitian ini dilakukan pada bulan MaretAgustus Tahun 2018. Lokasi dan tempat penelitian dilakukan di klinik Bidan Kristin Titi Papan kota Medan Jl. Titi Papan Medan Marelan Kota Medan. Populasi dan sampel dalam penelitian ini adalah ibu Primigravida yang melakukan kunjungan Pemeriksaan Kehamilan Di Klinik Bidan Kristin, dengan jumlah 30 Orang.

\section{HASIL}

\section{Pengetahuan ibu berdasarkan Pendidikan..}

Tabel 1. Distribusi frekuensi gambaran pengetahuan ibu primigravida tentang posisi dalam melahirkan di Klinik Bidan Kristin Titi Papan Kota Medan Tahun 2018 Berdasarkan Pendidikan $(n=30)$

\begin{tabular}{|c|c|c|c|c|c|c|c|c|c|}
\hline \multirow{3}{*}{ No } & \multirow{3}{*}{ Pendidikan } & \multicolumn{6}{|c|}{ Pengetahuan } & \multirow{2}{*}{\multicolumn{2}{|c|}{ Jumlah }} \\
\hline & & \multicolumn{2}{|c|}{ Baik } & \multicolumn{2}{|c|}{ Cukup } & \multicolumn{2}{|c|}{ Kurang } & & \\
\hline & & $\mathbf{F}$ & $\%$ & $\mathbf{F}$ & $\%$ & $\mathbf{F}$ & $\%$ & $\mathbf{F}$ & $\%$ \\
\hline 1. & SMA & 4 & 13,3 & 3 & 10 & 6 & 20 & 13 & 43,3 \\
\hline 2. & SMP & 1 & 3,3 & 12 & 40 & 1 & 3,3 & 14 & 46,7 \\
\hline 3. & SD & 1 & 3,3 & - & - & 2 & 6,7 & 3 & 10 \\
\hline & Total & 6 & $20 \%$ & 15 & $50 \%$ & 9 & $30 \%$ & 30 & $100 \%$ \\
\hline
\end{tabular}


Dari tabel 1 diatas diketahui bahwa tingkat pengetahuan ibu tentang posisi dalam melahirkan berdasarkan pendidikan yaitu mayoritas berpendidikan SMP sebanyak 14 orang $(46,7 \%)$, dan minoritas berpendidikan SD sebanayak 3 orang (10 $\%)$.

\section{Pengetahuan ibu berdasarkan Sumber Informasi.}

Tabel 2. Distribusi frekuensi gambaran pengetahuan ibu primigravida tentang posisi dalam melahirkan di Klinik Bidan Kristin Titi Papan Kota Medan Tahun 2018 Berdasarkan Sumber Informasi $(\mathbf{n}=30)$

\begin{tabular}{|c|c|c|c|c|c|c|c|c|c|}
\hline \multirow{3}{*}{ No } & \multirow{3}{*}{$\begin{array}{l}\text { Sumber } \\
\text { Informasi }\end{array}$} & \multicolumn{6}{|c|}{ Pengetahuan } & \multirow{2}{*}{\multicolumn{2}{|c|}{ Jumlah }} \\
\hline & & \multicolumn{2}{|c|}{ Baik } & \multicolumn{2}{|c|}{ Cukup } & \multicolumn{2}{|c|}{ Kurang } & & \\
\hline & & $\mathbf{F}$ & $\%$ & $\mathbf{F}$ & $\%$ & $\mathbf{F}$ & $\%$ & $\mathbf{F}$ & $\%$ \\
\hline 1. & T. Kesehatan & 5 & 16,7 & 9 & 30 & 8 & 26,7 & 22 & 73,3 \\
\hline 3. & Media & 1 & 3,3 & 4 & 13,3 & - & - & 5 & 16,7 \\
\hline 4. & Masyarakat & - & - & 2 & 6,7 & 1 & 3,3 & 3 & 10 \\
\hline & Total & 6 & $20 \%$ & 15 & $50 \%$ & 9 & $30 \%$ & 30 & $100 \%$ \\
\hline
\end{tabular}

Dari tabel 2 di atas diketahui bahwa tingkat pengetahuan ibu tantang posisi dalam melahirkan berdasarkan sumber informasi yaitu mayoritas mendapat infornasi dari tenaga kesehatan sebanyak 22 orang $(73,3$ $\%)$ dan minoritas mendapat informasi dari masyarakat sebanyak 3 orang $(10 \%)$.

\section{Pengetahuan ibu berdasarkan Paritas.}

Tabel 3. Distribusi frekuensi gambaran pengetahuan ibu primigravida tentang posisi dalam melahirkan di Klinik Bidan Kristin Titi Papan Kota Medan Tahun 2018 Berdasarkan Paritas $(\mathbf{n}=\mathbf{3 0})$

\begin{tabular}{|c|c|c|c|c|c|c|c|c|c|}
\hline \multirow{3}{*}{ No } & \multirow{3}{*}{ Paritas } & \multicolumn{6}{|c|}{ Pengetahuan } & \multirow{2}{*}{\multicolumn{2}{|c|}{ Jumlah }} \\
\hline & & \multicolumn{2}{|c|}{ Baik } & \multicolumn{2}{|c|}{ Cukup } & \multicolumn{2}{|c|}{ Kurang } & & \\
\hline & & $\mathbf{F}$ & $\%$ & $\mathbf{F}$ & $\%$ & $\mathbf{F}$ & $\%$ & $\mathbf{F}$ & $\%$ \\
\hline 1. & 1 Kali & - & - & - & - & 1 & 3,3 & 1 & 3,3 \\
\hline 2. & 2 Kali & - & - & 7 & 23,3 & 3 & 10 & 10 & 33,3 \\
\hline 3. & 3 Kali & 4 & 13,3 & 6 & 20 & 2 & 6,7 & 12 & 40 \\
\hline 4. & $>3$ Kali & 2 & 6,7 & 2 & 6,7 & 3 & 10 & 7 & 23,3 \\
\hline & Total & 6 & $20 \%$ & 15 & $50 \%$ & 9 & $30 \%$ & 30 & $100 \%$ \\
\hline
\end{tabular}

Dari tabel 4.1.3 diatas diketahui bahwa tingkat pengetahuan ibu tentang posisiposisi dalam melahirkan berdasarkan

\section{PEMBAHASAN}

\section{Pengetahuan ibu berdasarkan} pendidikan.

Berdasarkan hasil penelitian yang telah disajikan pada tabel 4.1.1 diatas, diketahui bahwa tingkat pengetahuan ibu hamil tentang posisi-posisi dalam melahirkan berdasarkan pendidikan mayoritas paritas yaitu mayoritas berparitas 3 kali sebanyak 12 orang $(40 \%)$ dan minoritas berparitas 1 kali sebanyak 1 orang $(3,3 \%)$ pedidikan SMP sebanyak 14 orang $(46,7 \%)$, dengan pengetahuan baik sebanyak 1 orang (3.3\%), cukup sebanyak 12 orang (40\%), kurang sebanyak 1 orang $(3,3 \%)$, dan minoritas pendidikan SD sebanyak 3 orang 
(10\%) dengan pengetahuan baik sebanyak 1 orang $(3,3 \%)$, dan pengetahuan kurang sebanyak 2 orang $(6,7 \%)$.

Menurut Hidayat (2005) menyatakan pendidikan merupakan penuntutan manusia untuk berbuat mengisi kehidupannya yang dapat digunakan untuk mendapatkan kualitas hidup, sebagaimana umumnya, semakin tinggi pendidikan seseorang maka

\section{Pengetahuan ibu berdasarkan Sumber Informasi,}

Berdasarkan hasil penelitian yang telah disajikan pada tabel 4.1.2 diatas diketahui bahwa tingkat pengetahuan ibu hamil tentang posisi-posisi dalam melahirkan berdasarkan sumber informasi mayoritas mendapatkan sumber informasi dari petugas kesehatan sebanyak 22 orang $(73,3 \%)$ dengan pengetahuan baik sebanyak 5 orang $(16,7 \%)$ cukup sebanyak 9 orang $(30 \%)$ dan kurang sebanyak 8 orang ( $26,7 \%)$, dan minoritas sumber informasi dari masyarakat sebanyak 3 orang $(10 \%)$ dengan pengetahuan cukup sebanyak 2 orang $(6,7$ $\%)$ dan berpengetahuan kurang sebanyak 1 orang $(3,3 \%)$.

Menurut Notoatmodjo (2003) menyatakan sumber informasi mempengaruhi

\section{Pengetahuan ibu berdasarkan Paritas.}

Berdasarkan hasil penelitian yang telah disajikan pada tabel 4.1.3 diatas diketahui bahwa tingkat pengetahuan ibu tentang posisi-posisi dalam melahirkan berdasarkan paritas mayoritas berparitas 3 kali sebanyak 12 orang $(40 \%)$ dengan pengetahuan baik sebanyak 4 orang $(13,3$ $\%)$ cukup sebanyak 6 orang $(20 \%)$ dan kurang sebanyak 2 orang $(6,7 \%)$ dan

\section{KESIMPULAN}

Gambaran pengetahuan ibu primigravida tentang posisi-posisi dalam melahirkan berdasarkan pendidikan mayoritas ibu berpedidikan SMP sebanyak 14 orang (46,7 $\%$ dan minoritas berpendidikan SD sebanyak 3 orang $(10 \%)$. Gambaran pengetahuan ibu primigravida tentang posisi-posisi dalam melahirkan berdasarkan sumber informasi mayoritas dari tenaga semakin mudah menerima informasi dan sebagus pengetahuan yang dimilikinya.

Menurut pendapat peneliti bahwa makin tinggi pendidikan seseorang maka ilmu pengetahuan lebih banyak, sehingga pengetahuan seseorang akan lebih baik dan semakin tinggi kesadaran untuk memilih posisi-posisi dalam melahirkan yang baik dan nyaman dirasakan ibu.

pengetahuan baik dari media maupun orang. Dalam keterkaitannya dengan kelompok manusia memberi kemungkinan untuk mempengaruhi anggota seseorang dalam proses pendidikan juga memperoleh pengetahuan melalui berbagai macam alat bantu media, akan membantu melakukan penyuluhan.

Menurut pendapat peneliti bahwa sumber informasi merupakan tingkat pengetahuan ibu, ibu berpenngetahuan baik dikarenakan rasa ingin tau ibu tinggi tentang posisiposisi dalam melahirkan sehingga ibu memperoleh pengetahuan dari tenaga kesehatan, media massa dan masyarakat.

minoritas berparitas 1 kali sebanayak 1 orang $(3,3 \%)$ dengan pengetahuan kurang sebanyak 1 oarang $(3,3 \%)$

Menurut selamet (2000) menyatakan paritas adalah angka-angka yang menunjukkan jumlah kelahiran yang di alami ibu.

Menurut pendapat peneliti bahwa paritas merupakan jumlah anak yang dilahirkan oleh seorang ibu.

kesehatan sebanyak 22 orang $(73,3 \%)$ dan minoritas ibu mendapatkan sumber informasi dari masyarakat sebanyak 3 orang (10 \%). Gambaran pengetahuan ibu primigravida tentang posisi-posisi dalam melahirkan berdasarkan paritas mayoritas ibu berparitas 3 kali sebanyaknya 12 orang (40 \%) dan minoritas ibu berparitas 1 kali sebanyak 1 orang $(3,3 \%)$ 


\section{DAFTAR PUSTAKA}

1. Asri, Dwi. 2012, Asuhan Persalinan Normal, Yogyakarta : Nuha Medika

2. Walsh, Linda V, 2007, Buku Ajar Kebidanan Komunitas, EGC, Jakarta.

3. Http://www.bidanku.com//diakses10juli2 018

4. Simkin, P, 2002, buku saku Persalinan, EGC, Jakarta.

5. Notoatmodjo, Soekidjo. 2012, Metodologi Penelitian Kesehatan, Jakarta : Rineka Cipta

6. Saifuddin AB, 2006, Acuhan Pelayanan Kesehatan Maternal Neonatal, Bina pustaka, Jakarta.

7. Sarwono, 2005, ilmu kebidanan, Tridasa pinter, Jakarta.

8. Wawan, 2011. Teori dan Pengukuran Pengetahuan, sikap, dan Perilaku Manusia, Yogyakarta : Nuha Medika [15] Yanti, 2010. Buku Ajar Asuhan

9. Kebidanan Persalinan, Yogyakarta : Pustaka Rihama

10.Hidayat, Asri. 2010, Asuhan Kebidanan Persalinan, Yogyakarta : Nuha Medika 
